06

\title{
Особенности локализации света неоднородной пленкой
}

\author{
(С) В.И. Иванов-Омский ${ }^{1}$, И.Е. Истомин ${ }^{1, \uparrow}$, M. Singh ${ }^{2}$, С.Г. Ястребов ${ }^{1}$ \\ ${ }^{1}$ Физико-технический институт им. А.Ф. Иофрфе РАН, Санкт-Петербург, Россия \\ ${ }^{2}$ Western University, London, Ontario, Canada \\ ฯ E-mail: kesha22ist@gmail.com
}

Поступило в Редакцию 22 марта 2021 г.

В окончательной редакции 10 апреля 2021 г.

Принято к публикации 11 апреля 2021 г.

Рассмотрен случай удержания света в тонкой неоднородной пленке аморфного углерода, легированного медью. Эффект проявляется из-за рассеяния света наночастицами меди, внедренными в пленку. Локализация объясняет усиление ,двухфононных“ линий поглощения инфракрасного излучения наноразмерными алмазами, одновременно присутствующими в пленке.

Ключевые слова: метаматериалы, наночастицы, локализация света в волноводе, усиление поглощения.

DOI: 10.21883/PJTF.2021.14.51180.18778

В последнее время возрос интерес к так называемым метаматериалам, т.е. к любым материалам, спроектированным таким образом, чтобы они имели некое свойство или набор свойств, которые не встречаются в материалах природного происхождения [1].

В качестве примера можно привести аморфный углерод, модифицированный металлами [2]. Такой материал получается методом совместного магнетронного распыления графитовой и металлической мишеней. Некоторые образцы поглощают радиоволны и поэтому могут быть использованы в качестве электромагнитных экранов. Эффект поглощения радиоволн был объяснен нами сравнительно недавно [2].

Другим интересным эффектом является аномальное увеличение интенсивности некоторых весьма слабых полос поглощения в инфракрасной (ИК) области спектра. Так, например, нами наблюдалось явление гигантского увеличения двухфононных полос поглощения наночастиц алмаза, присутствующих по нашим данным в этом материале как в исходном состоянии, так и при модификации его медью [3-6]. В работах [4,6] нами используются качественные модели, способные описать данное явление.

В настоящей работе мы объясняем возможную причину такого увеличения эффектами локализацииделокализации света в тонкой пленке синтезированного материала. Эта пленка представляет собой планарный волновод. Эффект захвата в волновод проявляется с помощью рассеяния света на наночастице (рис. 1). Из рисунка видно, что делокализация света, приводящая к его выводу из волновода, также может происходить благодаря механизму рассеяния на нанокластере. Очевидно, что эффект локализации приводит к значительному увеличению оптического пути. За рассеяние света могут быть ответственны крупные нанокластеры меди размером несколько десятков нанометров [7,8], редко, как это следует из литературы, встречающиеся в пленке. Из литературы также известно, что пленка содержит наноразмерные кластеры алмаза диаметром порядка $1 \mathrm{~nm}$ [9], которые практически не рассеивают свет. Форма наночастиц меди близка к сферической, поскольку для таких образцов наблюдался резонанс Фрелиха с энергией порядка $2 \mathrm{eV}[7,8]$. Если для оценки воспользоваться формулой Бугера $I=I_{0} \exp (-h \alpha)$, то при толщине пленки примерно $h=1 \mu \mathrm{m}$ в случае однократного прохождения света имеем пренебрежимо малое изменение интенсивности на выходе из образца $I$ по сравнению с падающим на него излучением $I_{0}$, если, как в случае массивного алмаза, коэффициент поглощения в области частот с волновыми числами $2000-2200 \mathrm{~cm}^{-1}$ принять равным $\alpha=14 \mathrm{~cm}^{-1}$ [10]. Однако в случае локализации света в волноводе при значительном расстоянии между наночастицами меди на входе и выходе света происходит заметное увеличение оптического пути (рис. 1).

Заметим, что из указанного выше следует, что в ИК-области $\sim 2000 \mathrm{~cm}^{-1}$ задачу об эффективной диэлектрической функции пленки $\xi_{\text {eff }}$ можно свести к задаче о смеси диэлектрических проницаемостей двух фаз, т.е. в рамках простой модели суммы двух компонент запишем

$$
\xi_{e f f}=\Theta \xi_{m}+(1-\Theta) \xi_{d} .
$$

Здесь $\Theta$ - объемная доля вклада матрицы, $\xi_{m}-$ диэлектрическая проницаемость матрицы, $\xi_{d}$ - диэлектрическая проницаемость алмаза. В рассматриваемом спектральном диапазоне мнимая часть $\zeta_{m}$ равна нулю, $\xi_{1 m}$ оценивалась по данным работы [7] и принималась равной 4. Точное значение $\Theta$ неизвестно. Однако если исходить из анализа электронно-микроскопических изображений алмазов в аморфном углероде, полученных с помощью просвечивающего электронного микроскопа в работе [9], можно принять для оценки, что наноалмазы занимают не менее 60 vol.\% образца. Таким образом, для мнимой части смеси можно записать выражение (индекс $m$ обозначает матрицу, цифры 1 и 2 - действительную и мнимую компоненты диэлектрической функции, 


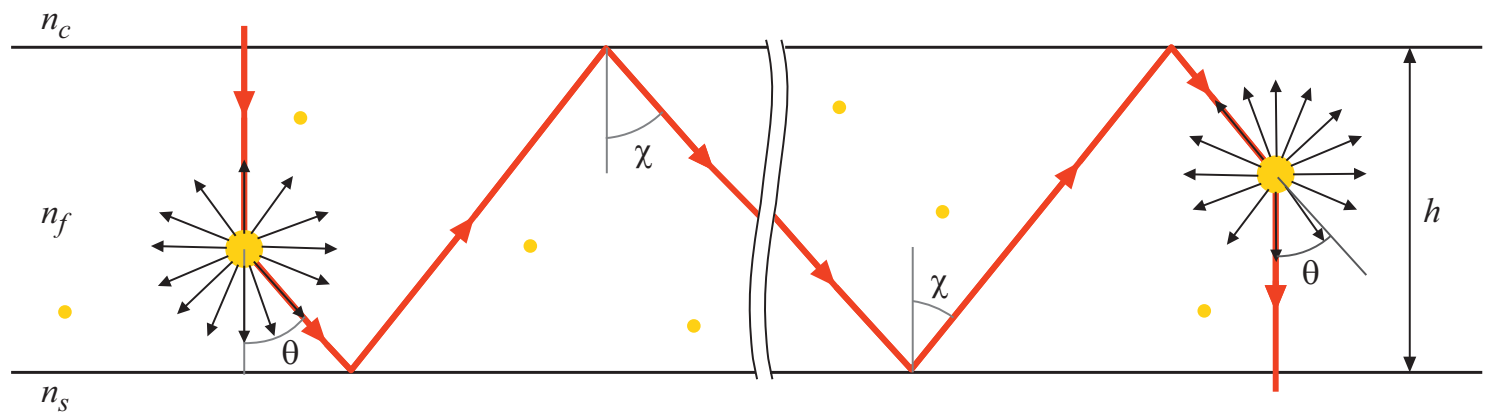

Рис. 1. Схема увеличения длины оптического пути при локализации света в планарном волноводе. $\chi$ и $\theta-$ модовый угол и угол рассеяния света соответственно. Мелкими точками обозначены наночастицы меди малых размеров (4 nm). Стрелками, расположенными вокруг кружка, показано рассеяние от крупной частицы меди $(40 \mathrm{~nm})$, приводящее из-за эффекта полного внутреннего отражения к локализации света волноводом (ловушкой).

$f$ - формфактор)

$$
\xi_{2 e f f}=(1-\Theta) \frac{\xi_{1 m}^{2} \xi_{2 d}}{\left(\xi_{1 m}+f_{j}\left(\xi_{1 d}-\xi_{1 m}\right)\right)^{2}+\left(f_{j} \xi_{2 d}\right)^{2}}
$$

Известно [11], что сильно вытянутые сфероиды (иглы) имеют $f_{1}=0$ вдоль иглы и $f_{2}=f_{3}=1 / 2$ поперек нее. У плоских эллиптических дисков $f_{1}=1$ по направлению нормали к поверхности и $f_{2}=f_{3}=0$ поперек нее. Из уравнения (2) следует, что для значения формфактоpa $f=0$ значение мнимой части максимально. Известно, что случай $f=0$ соответствует ситуации, когда электрическое поле электромагнитной волны направлено либо вдоль иглы, либо вдоль плоскости диска. Из указанного следует, что в случае, рассматриваемом в настоящей работе, наноалмазы представлены либо в форме дисков, либо в форме иголок. Заметим, что как в случае дисков, так и в случае иголок форма нанокристаллов отличается от формы наноалмазов, исследованных нами ранее для образца, не модифицированного металлами, методом просвечивающей электронной микроскопии [9], где она близка к сферической, т. е. глобулярной. Поэтому можно предположить, что в нашем случае добавление в образец меди способствует образованию нанокристаллов алмаза с формой, отличной от глобулярной.

Далее заметим, что теория планарного волновода достаточно подробно описана в [12].

Рассеяние на крупной частице меди (диаметром $40 \mathrm{~nm}$ ) приводит из-за эффекта полного внутреннего отражения к локализации света волноводом (рис. 1). В случае, показанном на рис. 1 , волновод граничит сверху с воздухом, а снизу - с подложкой. Исходя из условий эксперимента в волноводе распространяется электромагнитная волна с длиной $\lambda=4.5 \mu \mathrm{m}$. Подложка представляет собой кремний. Кремний покрыт слоем собственного окисла (показатель преломления $\left.n_{s} \approx 1.361[13]\right)$. Показатель преломления материала волновода оценивался в работе [7] и оказался равен $n_{f} \approx 2$. Показатель преломления воздуха $n_{c}$ считаем равным 1.

Из-за возможности реализации условий полного внутреннего отражения на границах раздела может проис- ходить локализация света в ловушке. Для распространения электромагнитной волны в волноводе необходимо, чтобы угол падения электромагнитной волны был больше углов полного внутреннего отражения на границе пленка-воздух $\left(\sin \chi_{c}=n_{c} / n_{f} \approx 27^{\circ}\right)$ и на границе пленка-подложка $\left(\sin \chi_{s}=n_{s} / n_{f} \approx 44^{\circ}\right)$. Далее введем общий для обеих границ модовый угол $\chi$ (он должен быть больше $\chi_{c}$ и $\chi_{s}$ ). Этот угол представляет собой решение дисперсионного уравнения для волновода.

Оценим возможность возбуждения мод планарного волновода. Воспользуемся условием поперечного резонанса

$$
k n_{f} h \cos \chi-\varphi_{s}-\varphi_{c}=\pi v,
$$

где $k-$ волновое число, $k=2 \pi / \lambda, h-$ толщина волновода, $\chi-$ угол падения электромагнитной волны, $v-$ натуральное число и нуль, определяющие порядок моды. Сдвиг фаз при отражении на границе пленка-покровный слой $\left(-2 \varphi_{c}\right)$ и сдвиг фаз при отражении на границе пленка-подложка $\left(-2 \varphi_{s}\right)$ для TE-моды волновода вычисляются по формулам

$$
\begin{gathered}
\varphi_{c}=\operatorname{atg}\left(\frac{\sqrt{n_{f}^{2} \sin ^{2} \chi-n_{c}^{2}}}{n_{f} \cos \chi}\right), \\
\varphi_{s}=\operatorname{atg}\left(\frac{\sqrt{n_{f}^{2} \sin ^{2} \chi-n_{s}^{2}}}{n_{f} \cos \chi}\right),
\end{gathered}
$$

а для ТМ-моды волновода - по формулам

$$
\begin{gathered}
\varphi_{c}=\operatorname{atg}\left(\left(\frac{n_{f}}{n_{c}}\right)^{2} \frac{\sqrt{n_{f}^{2} \sin ^{2} \chi-n_{c}^{2}}}{n_{f}^{2} \cos ^{2} \chi}\right), \\
\varphi_{s}=\operatorname{atg}\left(\left(\frac{n_{f}}{n_{c}}\right)^{2} \frac{\sqrt{n_{f}^{2} \sin ^{2} \chi-n_{s}^{2}}}{n_{f}^{2} \cos ^{2} \chi}\right) .
\end{gathered}
$$

В пленке толщиной $1 \mu \mathrm{m}$ (значение, типичное для получаемой в эксперименте толщины) будет возбуждаться только нулевая волноводная мода. Для моды волновода нулевого порядка $(v=0)$ из формулы (3) находим, что 
зависимость толщины от угла падения вычисляется по формуле

$$
h(\chi)=\frac{\varphi_{s}(\chi)+\varphi_{c}(\chi)}{k n_{f} \cos \chi},
$$

$\varphi_{s}(\chi)$ и $\varphi_{c}(\chi)$ для ТЕ-моды волновода вычисляются по формулам (4), а для ТМ-моды волновода - по формулам (5). Зависимость (6) справедлива для значений $\chi>\chi_{c}, \chi_{s}$.

Результат расчета по формуле (6) представлен на рис. 2. На этом рисунке приведены зависимости толщины пленки от угла падения нулевой моды электромагнитной волны для ТЕ- и ТМ-состояний поляризации.

Из рис. 2 видно, что удержание волноводом нулевой моды возможно только при значениях толщины пленки, превышающих 0.4 и $0.8 \mu \mathrm{m}$ для ТЕ- и ТМсостояний поляризации соответственно. Таким образом, для толщины пленки $1 \mu \mathrm{m}$ будут существовать нулевые TЕ- и ТМ-моды планарного волновода, различающиеся значением угла $\chi$.

Исходя из полученных данных можно оценить увеличение длины оптического пути $l$, необходимого для заметного эффекта. Для этой цели воспользуемся законом Бугера. Предполагая для оценки $l \alpha \approx 1$, получим $l \approx 714 \mu \mathrm{m}$, т. е. свет после захвата в волновод должен совершить порядка 250 отражений для нулевой моды и толщины пленки $1 \mu \mathrm{m}$ (рис. 2).

С использованием теории Ми [14] оказывается возможным оценить эффективность рассеяния света наночастицей меди внутрь волновода. Результат показан на рис. 3 для ТЕ-поляризации света. Картина рассеяния для ТМ-поляризации не приводится для краткости, поскольку практически совпадает с таковой для приведенного случая.

Мы также оценили рассеяние наночастицей меди размером $4 \mathrm{~nm}$. Картина рассеяния, что, естественно, по-

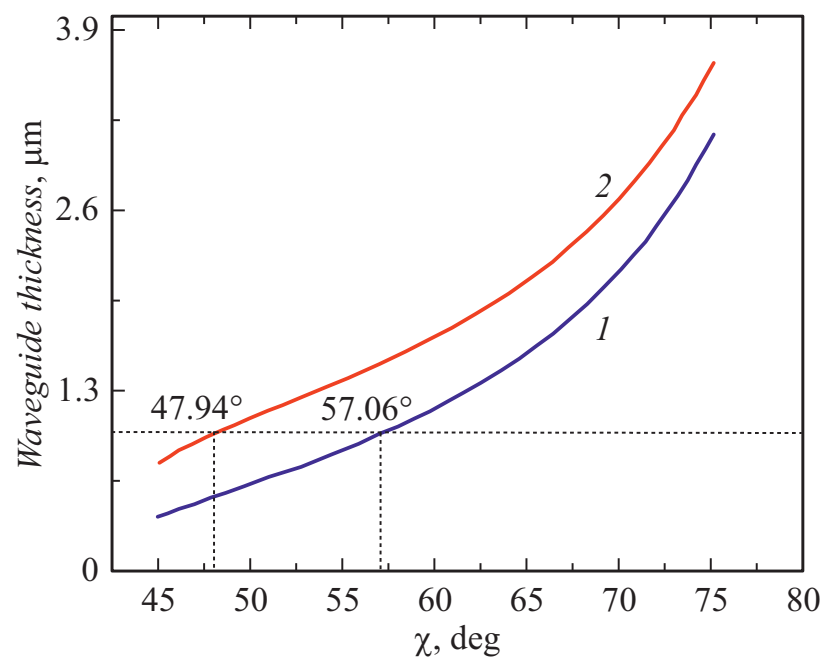

Рис. 2. Зависимость толщины планарного волновода от угла $\chi$ (см. рис. 1). 1 - для ТЕ-моды, 2 - для ТМ-моды. Пунктирной линией выделен результат расчета модовых углов для нулевой моды при толщине волновода, равной $1 \mu \mathrm{m}$.
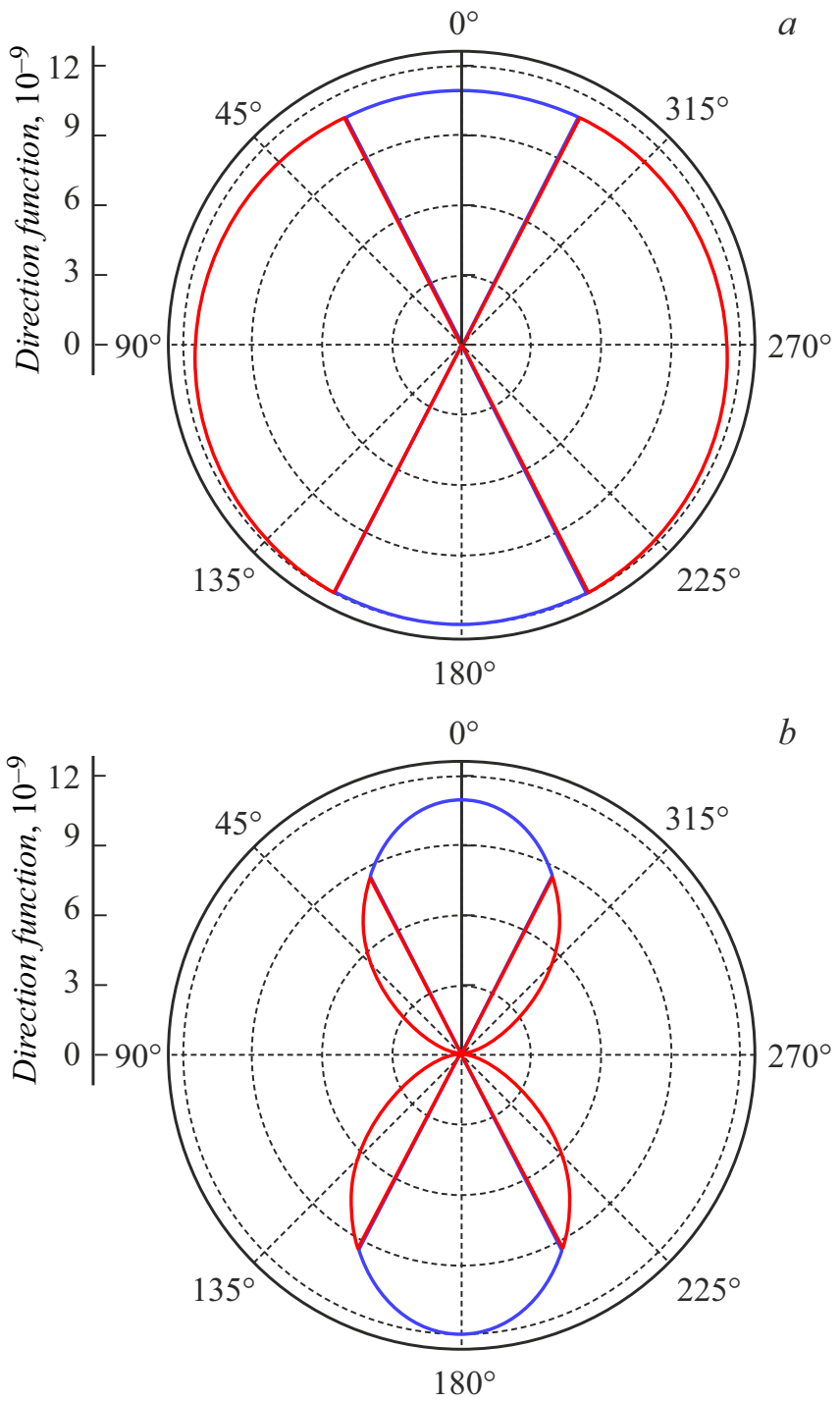

Рис. 3. Функция направленности для ТЕ-моды электромагнитной волны в зависимости от угла $\theta . a-$ в плоскости, параллельной плоскости поляризации падающего света; $b-$ в плоскости, перпендикулярной плоскости поляризации падающего света. Синим цветом обозначена часть рассеянной волны, которая выйдет из волновода, красным цветом обозначена часть рассеянной волны, которая останется в волноводе (цветной вариант рисунка приведен в электронной версии статьи).

добна приведенной на рис. 3. Однако его интенсивность на два порядка величины меньше.

Таким образом, ослабление света на ИК-частотах полос поглощения может являться следствием его захвата с последующим удержанием тонкой пленкой аналогично тому, как это происходит в планарном волноводе.

\section{Финансирование работы}

Один из авторов (M. Singh) благодарит Natural Sciences and Engineering Research Council of Canada (NSERC) за предоставление исследовательского гранта. 


\section{Конфликт интересов}

Авторы заявляют, что у них нет конфликта интересов.

\section{Список литературы}

[1] G. Singh, Rajni, A. Marwaha, Int. J. Eng. Trends Technol., 19 (6), 305 (2015). DOI: 10.14445/22315381/IJETT-V19P254

[2] С.Г. Ястребов, И.Е. Истомин, М. Singh, Письма в ЖТФ, 47 (2), 18 (2021). DOI: 10.21883/PJTF.2021.02.50539.18531

[3] В.И. Иванов-Омский, Т.К. Звонарева, Г.С. Фролова, ФТТ, 41 (2), 319 (1999).

[4] В.И. Иванов-Омский, С.Г. Ястребов, ФТТ, 41 (10), 1863 (1999).

[5] V.I. Ivanov-Omskii, Phil. Mag. B, 79 (2), 367 (1999).

[6] S.G. Yastrebov, R. Smith, V.I. Ivanov-Omskii, Phil. Mag. B, 80 (6), 1219 (2000).

[7] V.I. Ivanov-Omskii, A.V. Tolmatchev, S.G. Yastrebov, Phil. Mag. B, 73 (4), 715 (1996).

[8] Т.Н. Василевская, С.Г. Ястребов, Н.С. Андреев, И.А. Дроздова, Т.К. Звонарева, В.Н. Филипович, ФТТ, 41 (11), 2088 (1999).

[9] S.G. Yastrebov, V.I. Ivanov-Omskii, V.I. Siklitsky, A.A. Sitnikova, J. Non-Cryst. Solids, 227-230 (1), 622 (1998).

[10] J.R. Hardy, S.D. Smith, Phil. Mag., 6 (69), 1163 (1961).

[11] Ю.И. Петров, Физика малых частии, (Наука, М., 1982).

[12] Integrated optics, ed. by T. Tamir. Topics in Applied Physics (Springer, Berlin-Heidelberg, 1979), vol. 7, p. 333.

[13] I.H. Malitson, J. Opt. Soc. Am., 55 (10), 1205 (1965).

[14] К. Борен, Д. Хафмен, Поглощение и рассеяние света малыми частицами, пер. с англ. (Мир, М., 1986), c. $107-163$. 